\title{
Rancang Bangun Smart Bathroom Berbasis Raspberry Pi
}

\author{
Farid Pridiatama ${ }^{1}$, Maria Agustin ${ }^{2}$ \\ ${ }^{1,2}$ Politeknik Negeri Jakarta \\ ${ }^{1}$ farid.pridiatama.tik17@mhsw.pnj.ac.id, ${ }^{2}$ maria.agustin@tik.pnj.ac.id
}

\begin{abstract}
In the bathroom, in general, there is still much equipment that must be operated manually, such as turning on the bathroom lights using the conventional method by pressing the switch. In addition, to use the water faucet the user must turn the faucet so that water can come out when he wants to wash his hands or is filling the bath. Furthermore, there is another problem, namely in the use of soap during the Covid-19 pandemic, most of the use of liquid soap is still using the manual method, namely by pressing the soap container so that the soap can come out. To overcome these problems, a Smart Bathroom design was made that can make it easier for bathroom users by creating automatic features for lights, water faucets, and soap dispensers based on the Raspberry pi 3 model $b+$. In this design there are input devices in the form of PIR sensors and ultrasonic sensors then output devices in the form of lights, servo motors for pressing soap dispensers, and solenoid valves for automatic water faucets, and sensor reading results will be sent to the real-time database firebase and Telegram bot notifications. Based on the results of functional testing, the design of the Raspberry pi-based Smart Bathroom prototype tool has been able to work according to its function so that it can make it easier for bathroom users. The time it takes to send sensor read data to the Firebase real-time database for the four existing features is $2.8 \mathrm{~ms}-4.6 \mathrm{~ms}$.
\end{abstract}

Keywords: bathroom; firebase; sensorPIR; sensor ultrasonic; raspberry pi.

\begin{abstract}
ABSTRAK
Pada kamar mandi umumnya masih banyak peralatan yang harus dioperasikan secara manual, seperti menghidupkan lampu kamar mandi masih menggunakan cara kovensional dengan menekan sakelar. Selain itu, untuk menggunakan kran air pengguna harus memutarkran tersebut agar air dapat keluar ketikahendak mencuci tangan ataupun sedang mengisibak mandi. Selanjutnya terdapat masalah lain yaitu dalam peggunaan sabun pada masa pandemi Covid-19, kebanyakan penggunaansabun cair masih menggunakan cara manual yaitu dengan menekan wadah sabun agar sabun dapat keluar. Untuk mengatasi masalah- masalah tersebut, dibuatlah rancang bangun Smart Bathroom yang dapat memudahkan pengguna kamar mandi dengan cara membuat fitur otomatis pada lampu, kran air, dan dispenser sabun berbasis Raspberry pi 3 model b+. Pada rancangan ini terdapat perangkat inputberupa sensor PIR dan sensor ultrasonik laluperangkat output berupa lampu, motor servo untuk penekanan dispenser sabun, dan solenoid valve untuk kran air otomatis serta hasil baca sensor akan dikirim ke realtime database firebase dan notifikasi bot Telegram. Berdasalkan hasil pengujian fungsional perancangan alat prototype Smart Bathroom Berbasis Raspberry pi sudah dapat bekerja sesuai dengan fungsinya sehingga dapat memudahkan pengguna kamar mandi. waktu yang dibutuhkan untuk mengirim data hasil baca sensor ke realtime database Firebase untukkeempat fitur yang ada adalah 2,8 ms - 4,6 ms.
\end{abstract}

Kata kunci: kamar mandi; firebase; sensorPIR; sensor ultrasonic; raspberry pi.

\section{PENDAHULUAN}

Kemajuan teknologi yang pesat membuat masyarakat semakin mendambakan suatu alat yang mudah digunakan sebagaifasilitas, baik fasilitas pribadi maupun fasilitas umum. Hal ini menjadi pemicu berkembangnya peralatan yang semakin diharapkan dapat bekerja (penuh) secara otomatis. Namun saatkita memasuki kamar mandi rumah masih banyak peralatan yang harus dioperasikan secara manual, misalnya seperti menyalakan lampu kamar mandi, masih menggunakan cara konvensional dengan menekan tombol saklar. Selain itu, untuk menggunakan kran air, pengguna harus memutar kran agar air dapatkeluar saat ingin mencuci tangan atau sedang mengisi bak mandi, bahkan pengguna harus menunggu hingga bak terisi penuh. Selanjutnya ada permasalahan lain yaitu dalam penggunaan sabun, di masa pandemi Covid-19 sabun menjadi kebutuhan dalam upaya menjalankan protokol kesehatan. Sedangkan sebagian besar 
penggunaan sabun cair masih menggunakan cara manual yaitu dengan cara menekan wadah sabun agar sabun dapat keluar.

Untuk mengatasi permasalahantersebut, dibuatlah desain kamar mandi pintar yang dapat memudahkan pengguna kamar mandi dan mendukung upaya penerapan protokol kesehatan dengan mengurangi kontak fisik. Cara kerja smart bathroom ini adalah terdapat alat input berupa sensor PIR dan sensor ultrasonik, kemudian input yang diterima akan dikirimkan ke mikrokontroler berupa raspberry pi, kemudian raspberry pi akan mengolah data dan mengirimkannya. respon melalui alat keluaran berupa lampu, motor servo untuk menekan tempat sabun, dan katup solenoid pada kran air yang akan beroperasi secara otomatis. Data yang diterima oleh raspberry pi dari sensor ini akan dikirimkan secara real time ke database firebase melalui jaringan internet untuk mengetahui apakah perangkat berjalan dengan baik atau tidak, dan terdapat notifikasi melalui aplikasi Telegram yang akan memberitahukan kepada pengguna saat alat ini aktif. Sehingga dengan adanya alat ini akan membuat kamar mandi lebih hemat air, dan memudahkan pengguna kamar mandi karena peralatan seperti lampu, kran air, dan tempat sabun dapat bekerja secara otomatis.

\section{KERANGKA TEORI}

\subsection{Penelitian Sebelumnya}

Penelitian sebelumnya yang dilakukan oleh Astutik dan Djaeng (2017) berupa perancangan lampu otomatis menggunakan sensor PIR berbasis raspberry pi model 2 yang diterapkan pada rumah pintar. Rumah pintar ini menggunakan sistem lampu otomatis yang dilengkapi dengan sensor yang dapat mendeteksi gerakan sehingga akan menyala dan mati berdasarkan gerakan (Djaeng, D. S., \& Astutik, D., 2017).

Penelitian yang dilakukan oleh Purwanto, Darlis, dan Hartaman (2019) berupa perancangan dan implementasi smart bathroom berbasis IoT menggunakan NodeMCU, sensor PIR, dan sensor ultrasonik. Cara kerja sistem iniCara kerja sistem ini adalah, ketika sensor PIR (Passive Infra Red) mendeteksi adanya gerakan maka lampu dan exhaust fan menyala. Kemudian ketika sensor ultrasonik di bakmandi menghitung ketinggian air dan kondisi air kosong, katup solenoida menyala dan mengisi bak mandi sampai penuh. Kemudianketika sensor ultrasonik pada wadah shampo menghitung tinggi isi shampo dan kondisi shampo dalam keadaan kosong, maka alarm akan menyala dan memberi tahu pengguna. Kemudian data pada alat tersebut dihubungkan ke firebase sehingga semua data yang diterima oleh alat tersebut dapat ditampilkan secara real time (Purwanto, A. J., Darlis, D., \& Hartaman, A., 2019).

Penelitian yang dilakukan oleh Fonda, Wahyuni, dan Wiyono (2020) berupa perancangan kran wudhu otomatis dan pengisian tangki air otomatis di STMIK Hang Tuah Pekanbaru berbasis Arduino menggunakan sensor infra merah dan sensor Ping. Metode yang digunakan adalah prototype dengan bekerja pada pengisian tangki air otomatis, Sensor Ping berfungsi sebagai pengukur jarak antara posisi air dengan sensor dimana saat kapasitas air rendah maka mesin pompa air akan menyala dan saat air kapasitas penuh, mesin pompa air akan mati. Pada kranair otomatis sensor infra merah berfungsi sebagai pendeteksi objek tangan atau kakimanusia, jika ada yang terdeteksi maka air akankeluar melalui kran air dan jika tidak terdeteksi lagi maka kran akan otomatis menutup (Fonda, H., Wahyuni, R., \& Wiyono, I. (2020).

\subsection{Internet of Things}

Internet of Things atau sering disebut IoT adalah sebuah ide dimana semua objek di dunia nyata dapat saling berkomunikasi sebagaibagian dari suatu sistem yang terintegrasi dengan menggunakan jaringan internet sebagai penghubung. Misalnya, CCTV yang dipasangdi sepanjang jalan terhubung dengan koneksiinternet dan disatukan 
dalam ruang kendali yang jaraknya mungkin puluhan kilometer atau rumah pintar yang dapat dikelola melalui smartphone dengan bantuan koneksi internet. pada dasarnya perangkat IoT terdiri dari sensor sebagai media pengumpulan data, koneksi internet sebagai media komunikasi, dan server sebagai pengumpul informasi yang diterima oleh sensor dan untuk dianalisis (Efendi, Y., 2018).

\subsection{Smart Home}

Menurut Purwanto, Darlis, dan Hartaman (2019) Rumah Pintar adalah aplikasi gabungan antara teknologi dan layanan yang dikhususkan untuk lingkungan rumah denganfungsi tertentu yang bertujuan untuk meningkatkan keamanan, efisiensi, dan kenyamanan penghuninya (Purwanto, A. J., Darlis, D., Hartaman, A., 2019). Sistem rumah pintar biasanya terdiri dari perangkat pemantauan, perangkat kontrol dan secara otomatis ada beberapa perangkat yang dapat diakses menggunakan computer (Masykur, F., \& Prasetiyowati, F., 2016).

\subsection{Prototyping}

Prototyping adalah metodepengembangan perangkat lunak yang berupa model fisik kerja sistem dan berfungsi sebagai versi awal dari sistem. Dengan metodeprototyping ini akan dihasilkan sebuah sistem prototipe sebagai perantara bagi pengembang dan pengguna sehingga dapat berinteraksi dalam proses kegiatan pengembangan sistem informasi. Tujuan pembuatan prototipe bagi pengembang sistem adalah untuk mengumpulkan informasi dari pengguna sehingga pengguna dapat berinteraksi dengan model prototipe yang dikembangkan, karena prototipe menggambarkan versi awal sistem untuk kelanjutan sistem yang lebih besar secara aktual (Maulindar, J., \& Nurohman, 2020).

\subsection{Raspberry Pi}

Raspberry pi (Single Board Circuit) yang merupakan komputer papan tunggal, memiliki ukuran sebesar kartu kredit. RaspberryPi ini mampu bekerja seperti komputer padaumumnya yang menggunakan sistem operasi Raspbian, dengan prosesor ARM11 700MHz.Ada dua jenis Raspberry Pi yaitu tipe A dan B. Perbedaannya terletak pada kapasitas memoriyang digunakan untuk tipe A 256MB dan tipe B 512MB. Penyimpanan data tidak menggunakan hard disk melainkan SD card. Ini juga dilengkapi dua port USB, konektor HDMI dan port ethernet. Raspberry pi membutuhkan energi 5V dengan arus minimal 700mA untuk tipe B dan 500mA untuk tipe A (Kurniawan, D. E., \& Fani, S., 2017).

\subsection{Sensor Ultrasonik}

Sensor ultrasonik atau sensor jarakadalah sensor yang mampu mendeteksi keberadaan objek terdekat tanpa kontak fisik. Sensor jarak bekerja berdasarkan prinsip pemantulan gelombang suara sehingga dapat menginterpretasikan jarak suatu benda denganfrekuensi tertentu. Prinsip kerja dari sensor ini adalah pemancar mengirimkan gelombang ultrasonik kemudian diukur dengan waktu yang diperlukan untuk pantulan datang dari objek. Lamanya waktu ini sebanding dengan dua kali jarak sensor ke objek (Purwanto, A. J., Darlis, D., \& Hartaman, A., 2019).

\subsection{Sensor PIR}

Sensor PIR berfungsi sebagai pendeteksi gerakan, bekerja dengan mendeteksi pergerakan di sekitar area pengawasan. Sensor PIR (motion) sering dijumpai dalam kehidupan sehari-hari, misalnya pada pintu mall, bank atau gedung perkantoran dimana pintu tersebut terbuka dengan sendirinya. Komponen yang digunakan pada sensor 
gerak ini disebut Passive Infrared Sensor (PIR). Komponen sensor gerak ini memiliki faktor bentuk yang kecil, konsumsi daya yang rendah, dan tidak cepat aus (Kurniawan, D. E., \& Fani, S., 2017).

\subsection{Firebase}

Firebase adalah layanan yang dimiliki oleh Google. Dengan firebase, pengembang aplikasi dapat fokus pada pengembangan aplikasi dan menyederhanakan pengembangan aplikasi. Firebase memiliki beberapa fitur antara lain real-time database yang disimpan di cloud, layanan ini menggunakan application program interface (API), data disimpan sebagai JSON dan disinkronkan secara realtime ke setiap clientyang terhubung, jika terjadi perubahan pada datatersimpan, maka setiap pengguna yangterhubung akan menerima pembaruan data secara otomatis (Purwanto, A. J., Darlis, D., \& Hartaman, A., 2019).

\subsection{Telegram}

Telegram adalah aplikasi perpesanan multi-platform berbasis cloud gratis dan nirlaba. Telegram tersedia di platform seluler (Android, iOS, Windows Phone, Ubuntu Touch) dan desktop (Windows, OS X, Linux). Telegram juga menyediakan enkripsi end-to-end opsional (Irsyam, M. \& Tanjung, A., 2019). Telegram Bot dirancang untuk dapat mengoperasikan pesan secara otomatis. Untukdapat berinteraksi dengan bot, pengguna cukup mengirimkan pesan perintah (command) melaluipesan pribadi atau grup. Dalam membuat akun Bot Telegram tidak memerlukan nomor telepon tambahan dan hanya berfungsi sebagaiantarmuka untuk kode yang berjalan di server. Bot dapat memberikan informasi penagihan, memberikan informasi atas permintaan pengguna ke agensi mereka dan banyak hal lain seperti untuk mengajarkan sesuatu, bermain, menyiarkan, sebagai pengingat, dan bahkandapat mengirim perintah ke perangkat Internet of Things (Hadikristanto, W., \& Suprayogi, W., 2019).

\subsection{Solenoid Valve}

Solenoid valve adalah katup yang digerakkan oleh energi listrik, memiliki kumparan sebagai penggeraknya yang berfungsi untuk menggerakkan katup magnet yang dapat digerakkan oleh arus AC atau DC. Solenoid Valve adalah kran yang bekerja ketika input ke rangkaian solenoid valve mendapat sinyal tinggi sehingga mengaktifkan kerja klep yang terdapat pada kran listrik. Pada tugas akhir ini, solenoid valve berfungsi untuk membuka dan menutupkran (Purwanto, A. J., Darlis, D., \& Hartaman, A., 2019).

\subsection{Servo Motor}

Motor servo adalah perangkat yang terdiri dari motor DC, rangkaian roda gigi, rangkaian kontrol, dan potensiometer. Rangkaian roda gigi yang terpasang pada poros motor DC akan memperlambat putaran poros dan meningkatkan torsi motor servo, sedangkan potensiometer dengan perubahan tahanan saat motor berputar berfungsi sebagai penentu batas posisi servo. putaran poros motor. Sudut sumbu motor servo diatur berdasarkan lebar pulsa pada pin kontrol motor servo (Latifa, U., \& Saputro, J. S., 2018).

\subsection{Relay}

Relay adalah saklar elektronik yang dapat membuka atau menutup suatu rangkaian dengan menggunakan kendali dari rangkaian elektronik lain. Relay terdiri dari kumparan, pegas, saklar (terhubung ke pegas) dan 2 kontak elektronik (biasanya tertutup dan biasanya terbuka), berdasarkan prinsip dasar cara kerjanya, relai dapat bekerja karena adanya medan magnet. digunakan untuk menggerakkan saklar. Ketika kumparan diberi tegangan kerja relay, maka akan timbul medan magnet pada kumparan tersebut karena adanya arus yang mengalir pada kumparan kawat tersebut. 
Kumparan yang bertindak sebagai elektromagnetkemudian akan menarik saklar dari kontak NC ke kontak NO. jika tegangan pada kumparan dimatikan maka medan magnet pada kumparan akan hilang sehingga pegas akan menarik saklar ke kontak NC (Isfarizky, Z., Fardian, \& Mufti, A., 2017).

\subsection{Flowchart}

Flowchart menggambarkan urutan logis dari suatu prosedur pemecahan masalah (Sitorus, L., 2015), sehingga diagram alir adalah langkah-langkah pemecahan masalah yang ditulis dalam simbol- simbol tertentu. Flowchart juga berguna sebagai fasilitas untuk berkomunikasi antara programmer yang bekerja dalam tim proyek danmembantu mengkomunikasikan jalannya program kepada orang lain (bukan programmer)dengan lebih mudah (Santoso, \& Nurmalina, R., 2017).

\section{METODOLOGI}

\subsection{Metode Pengembangan Perangkat Lunak}

Metode yang digunakan dalam pelaksanaan tugas akhir ini adalah metode prototyping karena hasil akhir dari sistem ini adalah prototype. Pelaksanaan skripsi denganmenggunakan metode prototyping memiliki tahapan sebagai berikut:

\section{A. Pengumpulan Kebutuhan}

Pada tahap ini dilakukan analisis terhadap komponen perangkat keras dan perangkat lunakyang dibutuhkan dalam membangun sistem smart bathroom melalui studi literatur.

\section{B. Proses Desain Cepat}

Membuat desain prototype berdasarkan hasil analisis kebutuhan yang merepresentasikan cara kerja dan skema rangkaian sebagai pedoman dasar dalam pembuatan prototype melalui pembuatan flowchart dan block diagram.

\section{Membangun Prototype}

Pada tahap ini dibuat prototype alat sebagai proses mewujudkan desain yang telah dibuat dengan cara menghubungkan semuaperangkat menjadi satu kesatuan yang membentuk sistem desain Smart Bathroom Berbasis Raspberry Pi.

D. Evaluasi dan Perbaikan

Tahap terakhir dalam metode prototyping adalah mengevaluasi dan memperbaiki hasil pengujian prototipe sistem Rancang Bangun Smart Bathroom Berbasis Raspberry Pi agar dapat mengetahui apakah sistem berjalan sesuaidengan yang dirancang atau tidak.

\section{HASIL PEMBAHASAN}

\subsection{Deskripsi Alat}

Prototipe Rancang Bangun Smart Bathroom ini memiliki 4 fitur utama yaitu kran air otomatis, kran bak air otomatis, tempat sabun otomatis, dan lampu otomatis. Fitur-fitur tersebut terdiri dari 3 perangkat utama, yaitu perangkat input, proses dan output. Perangkat input terdiri dari beberapa modul seperti sensor ultrasonik yang berfungsi untuk mendeteksi perubahan jarak, kemudian sensor pir yang berfungsi untuk mendeteksi pergerakan kemudian hasil 
pembacaan sensor akan dikirimkan ke perangkat proses yaitu mikrokomputer raspberry pi untuk dioperasikan. perangkat output dan mengirimdata dari sensor ke database firebase. Hasil pengolahan akan dieksekusi pada perangkat keluaran yang meliputi relay, lampu, katup solenoid valve otomatis, dan motor servo, serta untuk memastikan sistem aktif atau tidak akan ditampilkan notifikasi melalui bot Telegram. Selanjutnya database firebase real time akan menampilkan hasil pembacaan sensor.

\subsection{Cara Kerja Sistem}

Cara kerja alat prototipe Rancang Bangun Smart Bathroom Berbasis Raspberry Piini setelah raspberry diaktifkan maka raspberry akan melakukan proses konektivitas ke jaringaninternet. Selanjutnya cek apakah raspberry pi sudah terhubung dengan jaringan internet, jika tidak terhubung dengan jaringan internet maka proses koneksi akan dilakukan kembali agar raspberry dapat diakses melalui remote access. Kemudian sistem akan melakukan inisialisasiuntuk mengaktifkan semua variabel yang telah dimasukkan ke dalam program. Jika program sedang berjalan, sistem akan mengirimkan notifikasi "System ON" melalui bot Telegram. Kemudian akan dilanjutkan ke proses sistem Smart Bathroom yang terdiri dari 4 fitur yaitu kran air otomatis, kran bak otomatis, tempatsabun otomatis, dan lampu otomatis. Selanjutnya jika tidak ada perintah exit programoleh user maka proses sistem smart bathroom akan terus berulang atau berulang, namun jika user mengeksekusi perintah exit program maka sistem selesai dan akan muncul notifikasi "System Off" pada bot Telegram. Alur dari cara kerja sistem dijelaskan pada flowchart yang ditampilkan di Gambar 1.

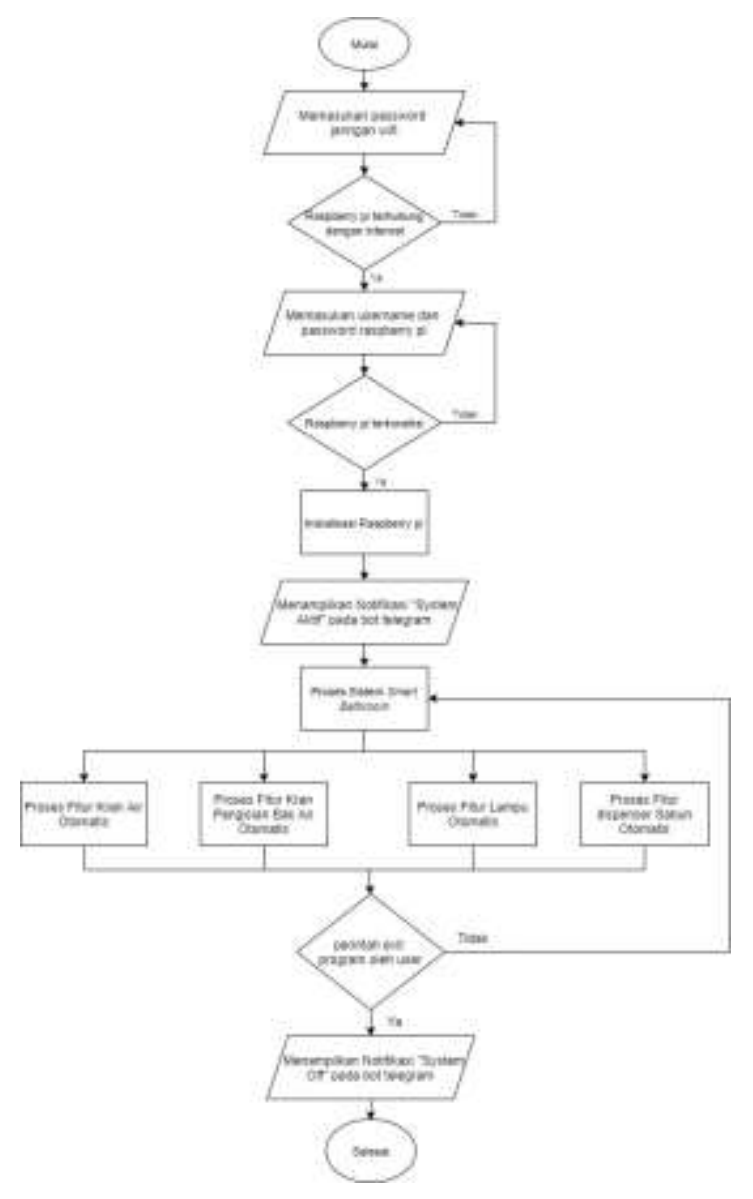

Gambar 1. Flowchart Sistem 


\subsection{Blok Program}

Diagram blok sistem untuk menggambarkan skema dan koneksi untuk setiap blok komponen dalam sistem ini disajikan pada Gambar 2.

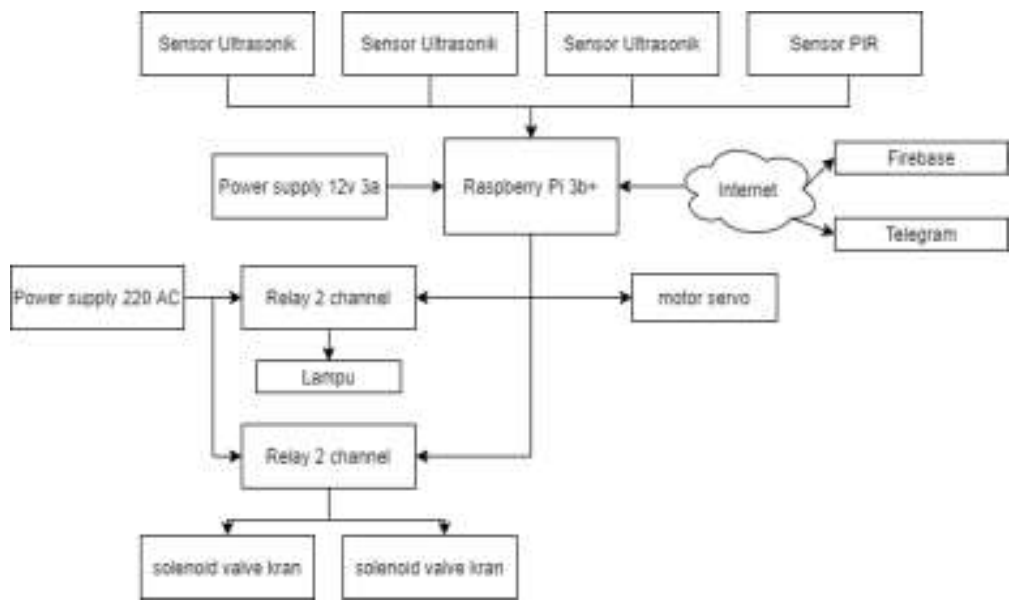

Gambar 2. Blok Diagram

\subsection{Realisasi Alat Prototipe}

Dari detail perencanaan yang meliputi deskripsi, cara kerja, serta blok diagram alat, realisasi prototipe alat diawali denganperancangan rangkaian modul yang terhubung dengan raspberry pi 3b+. Komponen yang digunakan pada rangkaian prototipe alat kamar mandi pintar berbasis raspberry pi ini terdiri dari:

- Raspberry Pi 3b+

- Ultrasonic Sensor

- PIR Sensor

- Relay 2 channel

- Motor Servo sg90

- Solenoid Valve

- Lampu

Rancangan alat yang akan direalisasikan disajikan pada Gambar 3 desain skematik dan hasil realisasi alat disajikan pada Gambar 4 berikut:

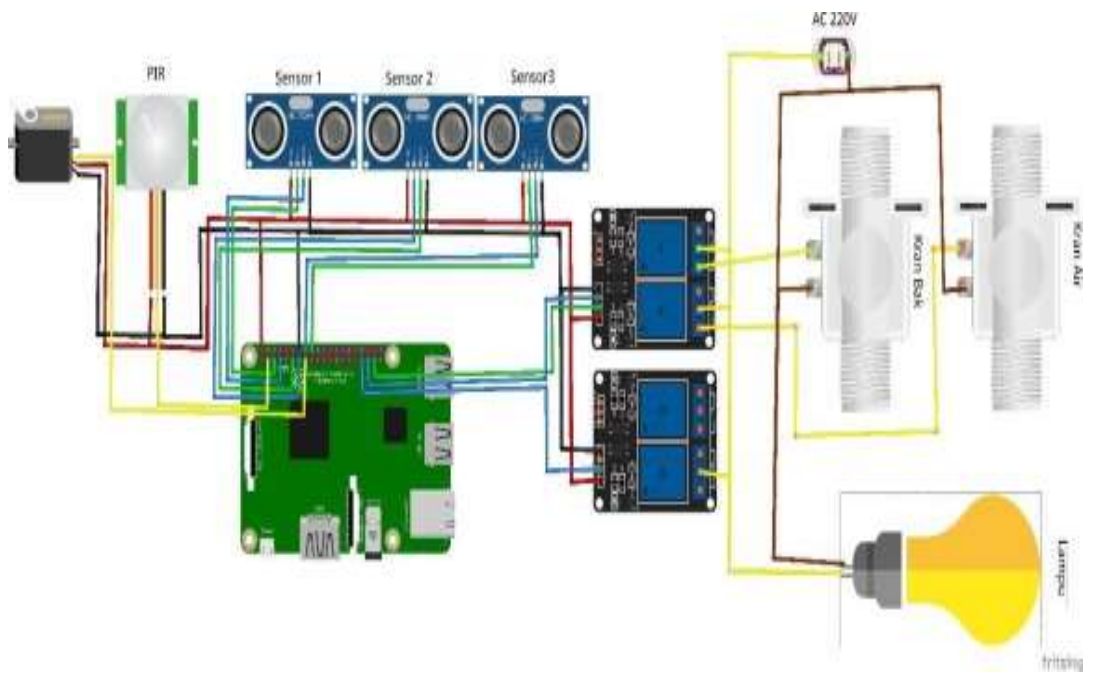

Gambar 3. Desain Skematik 


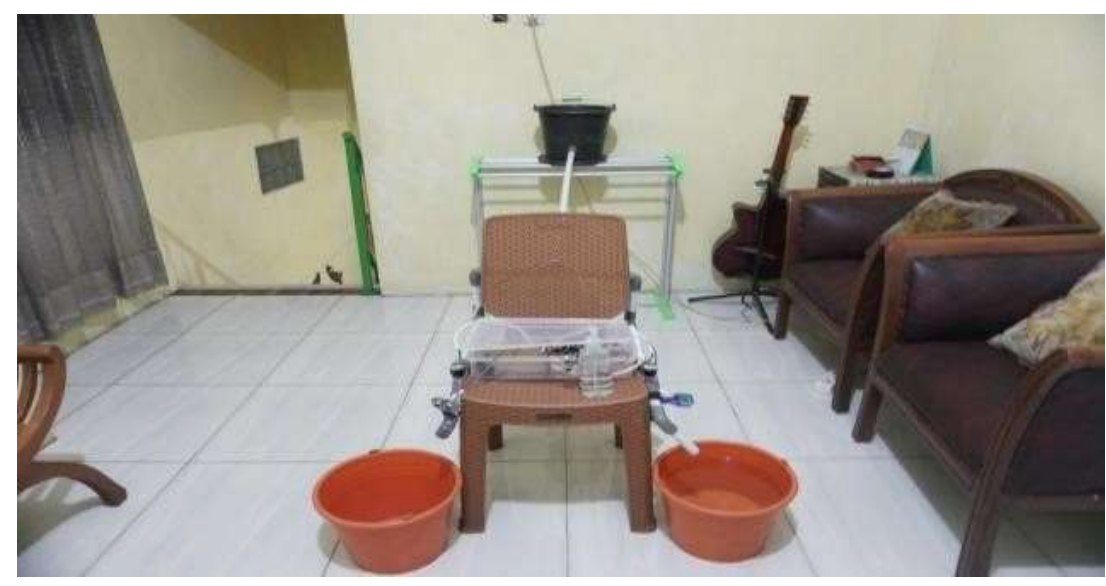

Gambar 4. Smart Bathroom

\subsection{Realisasi Program}

Pembuatan algoritma dan juga fungsilogika untuk berjalannya sistem pada perangkat yang telah dirakit. Program ini terdiri dari beberapa bagian, antara lain inisialisasi library, port, variabel yang digunakan, fungsi, membuat database, dan membuat notifikasi Bot telegram. Gambar 5 menampilkan tampilan program multi.py saat dijalankan sebagai berikut:

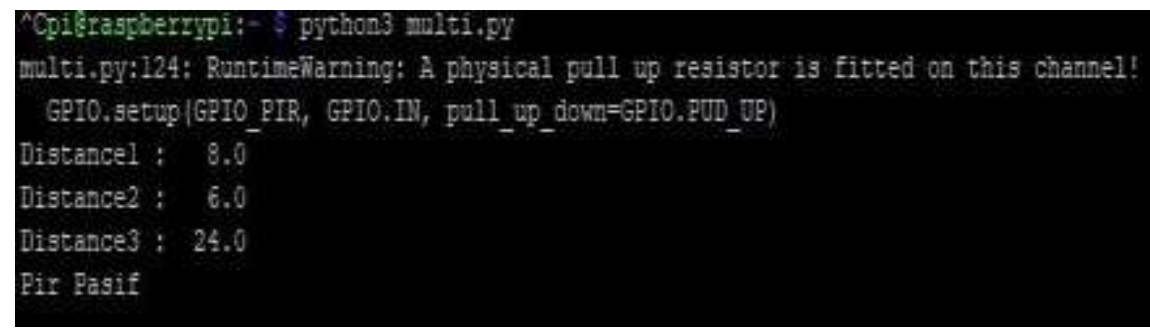

Gambar 5. Tampilan Program

Membuat notifikasi Bot telegram seperti yang disajikan pada Gambar 6 berikut:

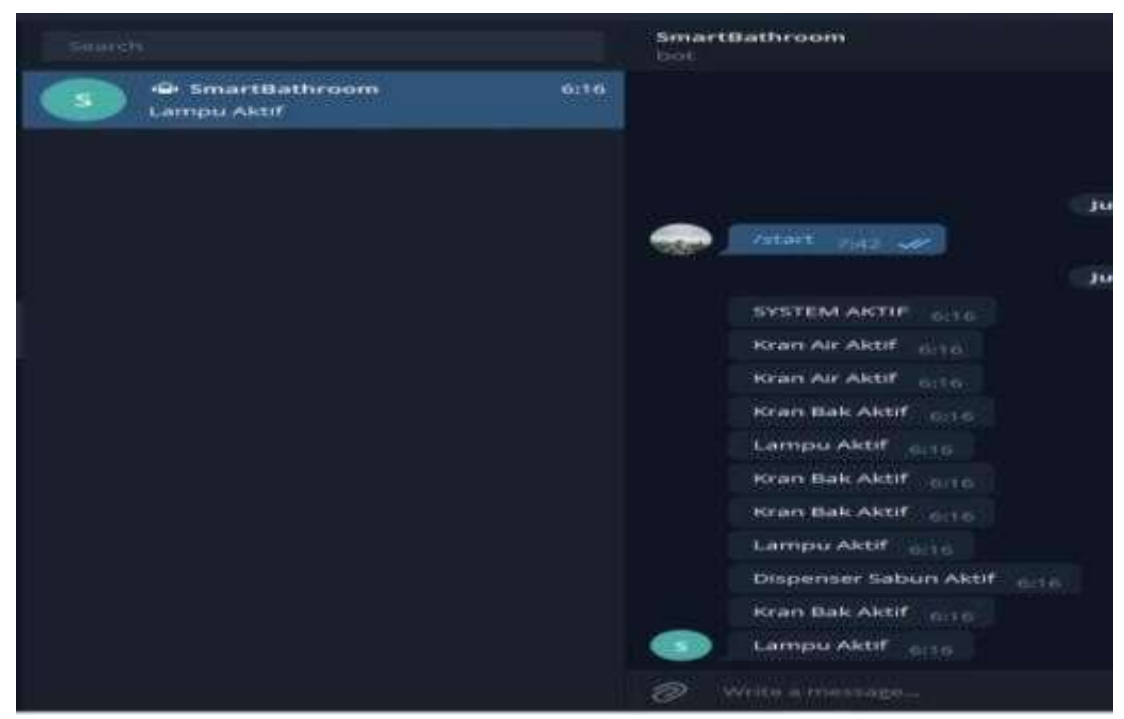

Gambar 6. Notifikasi Telegram 
Membuat database seperti yang disajikan pada Gambar 7 berikut:

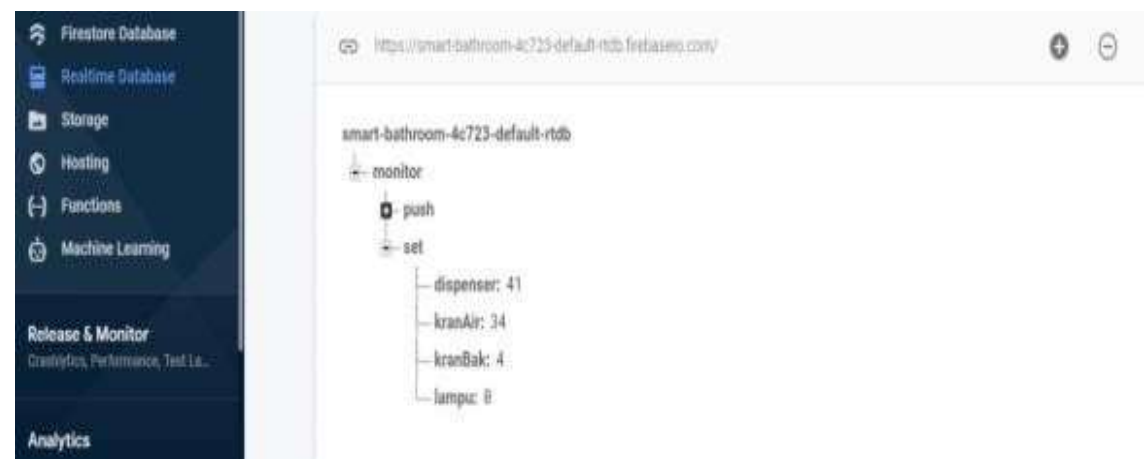

Gambar 7. Realtime Database Firebase

\subsection{Pengujian}

Pengujian pada prototype Smart Bathroom Berbasis Raspberry pi bertujuan untuk mengetahui apakah alat prototype telah berfungsi sesuai dengan yang diharapkan atau belum. Dilakukan 2 pengujian untuk menguji prototype alat yang telah dibuat yaitu: Pengujian Fungsional dan Pengujian Respons Waktu, dengan penjelasan berikut:

1. Prosedur Pengujian Fungsional

Pengujian fungsional dilakukan dengan menguji fungsi dari fitur-fitur yang ada pada alat prototipe Smart Bathroom Berbasis Raspberry pi untuk setiap komponen yang terpasang. Dari hasil pengujian akan didapatkan data yang dapat digunakan sebagai dasar untuk menentukan tingkat akurasi sistem dalam mendeteksi jarak objek, pergerakan manusia, pengiriman data ke database firebase dan notifikasi pada bot Telegram.

2. Prosedur Pengujian Respons Waktu

Pengujian respons waktu dilakukan untuk mengetahui tingkat kecepatan sistemdalam mengirimkan data ke firebase realtime database. Pengukuran waktu dilakukan dengan menghitung interval antara waktu sejak sistem mendeteksi pembacaan sensor dan waktu sistemberhasil mengirimkan data ke firebase realtime database.

\subsection{Analisis Hasil Pengujian}

1. Pengujian Fungsional

Tujuan dari pengujian ini adalah untuk memastikan bahwa setiap bagian sesuai dengan alur proses yang ditentukan dan memastikan bahwa semua kesalahan input yang dilakukan oleh pengguna dapat ditangani oleh sistem. Berdasarkan hasil pengujian fungsional yang telah dilakukan terhadap fungsi fitur pada alat prototipe Smart Bathroom Berbasis Raspberry pi untuk setiap komponen yang terpasang, data menunjukkan bahwa fungsionalitas sistem secara keseluruhan dapat berjalan dengan baik dan sesuai dengan yang diharapkan.

\section{Pengujian Respon Waktu}

Data respons waktu yang diperoleh diolah untuk mendapatkan berapa lama waktu yang dibutuhkan sistem untuk mengirimkan data pembacaan sensor ke Firebase realtime database setelah sistem berhasil mendeteksi jarak dan pergerakan manusia. Besarnya waktu diperoleh dari rata-rata waktu yang dibutuhkan untuk semua percobaan yang dilakukan. Untuk menghitung rata-rata dapat dilakukan dengan perhitungan sebagai berikut: 


$$
\text { Rata }- \text { rata waktu }=\frac{\text { Jumlah Selisih Waktu }}{\text { Banyak Percobaan }}
$$

Pengujian respons waktu dari sensor ultrasonik Kran Air Otomatis ke Firebase

$$
\text { Rata }- \text { rata waktu }=\frac{46}{10}
$$

Hasil perhitungan menunjukkan bahwa rata-rata waktu yang dibutuhkan sistem untuk mengirimkan data pembacaan sensor ke database realtime adalah 4,6 ms (milisekon).

Pengujian respons waktu dari sensor ultrasonik Kran Bak Otomatis ke Firebase

$$
\text { Rata }- \text { rata waktu }=\frac{37}{10}
$$

Hasil perhitungan menunjukkan bahwa rata-ratawaktu yang dibutuhkan sistem untuk mengirimkan data pembacaan sensor ke database realtime adalah 3,7 ms (milisekon).

Pengujian respons waktu dari sensor ultrasonik Dispenser Sabun Otomatis ke Firebase

$$
\text { Rata }- \text { rata waktu }=\frac{28}{10}
$$

Hasil perhitungan menunjukkan bahwa rata-ratawaktu yang dibutuhkan sistem untuk mengirimkan data pembacaan sensor ke database realtime adalah 2,8 ms (milisekon).

Pengujian respons waktu dari sensor PIRLampu Otomatis ke Firebase

$$
\text { Rata }- \text { rata waktu }=\frac{32}{10}
$$

Hasil perhitungan menunjukkan bahwa rata-ratawaktu yang dibutuhkan sistem untuk mengirimkan data pembacaan sensor ke database realtime adalah 3,2 ms (milisekon).

\section{KESIMPULAN}

Berdasarkan hasil penelitian yang telah dilakukan maka dapat ditarik beberapa kesimpulan, yaitu: Perancangan alat prototipe Smart Bathroom Cerdas berbasis Raspberry pi sudah dapat bekerja sesuai fungsinya sehingga dapat memudahkan pengguna kamar mandi dan mendukung upaya penerapan protokol kesehatan dengan mengurangi kontak fisik, rata-rata waktu yang dibutuhkan sistem dalam mengirim data hasil baca sensor ke realtime database Firebase untuk keempat fitur yang ada pada sistem adalah 2,8 ms - 4,6 ms (millisekon). Untuk pengembangan selanjutnya,database sistem Smart Bathroom yangsudah dibuat dapat dikembangkan lagi menjadi aplikasi android, penggunaan solenoid valve kran otomatis lebih cocok digunakan untuk kran yang sumber airnya dari pompa atau toren, memaksimalkan sistem apabila terjadi internet mati atau listrik mati.

\section{DAFTAR PUSTAKA}

Djaeng, D. S., \& Astutik, D., 2017. Rancang Bangun Lampu Otomatis Dengan Sensor Passive Infra Red (PIR) Berbasis Raspberry Pi. Jurnal Elektronik Sistem Informasi dan Komputer, 3(2)

Efendi, Y., 2018. Internet of Things (IOT) Sistem Pendalian Lampu MenggunakanRaspberry Pi Berbasis Mobile. Jurnal Ilmiah Ilmu Komputer, 4(1), 20.

Fonda, H., Wahyuni, R., \& Wiyono, I. (2020). Rancang Bangun Kran WudhuOtomatis dan Pengisian Tank Air 
Otomatis Pada STMIK Hang Tuah Pekanbaru Berbasis Arduino UNO. JURNAL ILMUKOMPUTER, 9(2), 107116.

Hadikristanto, W. \& Suprayogi, W., 2019. Penerapan Internet of Things (IoT) PadaSistem Kontrol Lampu Gedung Menggunakan NodeMCU Berbasis

Irsyam, M. \& Tanjung, A., 2019. Sistem Otomasi Penyiraman Tanaman BerbasisTelegram. Sigma Teknika, 2(1), 8194.

Isfarizky, Z., Fardian, \& Mufti, A., 2017. Rancang Bangun Sistem Kontrol Pemakaian Listrik Secara Multi Channel Berbasis Arduino (Studi Kasus Kantor LBH Banda Aceh). KITEKTRO: Jurnal Online Teknik Elektro, 31

Kurniawan, D. E., \& Fani, S., 2017. Perancangan Sistem Kamera Pengawas Berbasis Perangkat Bergerak Menggunakan Raspberry Pi. Jurnal Ilmiah Teknologi Informasi Terapan, 141.

Latifa, U., \& Saputro, J. S., 2018. Perancangan Robot Arm Gripper Berbasis Arduino UNO Menggunakan Antarmuka Labview. Journal Unsika, 139. Jusuf, H., 2015. Penggunaan Secure Shell (SSH) Sebagai Sistem Komunikasi Aman Pada Web Ujian Online. Bina Insani ICTJournal (OLD), 2(2), 75-84.

Masykur, F., \& Prasetiyowati, F. (2016).Aplikasi Rumah Pintar (Smart Home) Pengendali Peralatan Elektronik RumahTangga Berbasis Web. Jurnal Sains, Teknologi dan Industri, 14(1), 93-100.

Maulindar, J., \& Nurohman. (2020).Prototype "Smart Card Shop" UntukTransaksi Belanja Digital. Jurnal Dinamika Informatika, 1-14.

Purwanto, A. J., Darlis, D., \& Hartaman, A.(2019). Perancangan Dan IimplementasiSmart Bathroom Berbasis IOT. e-Proceeding of Applied Science, 1620.

Santoso, \& Nurmalina, R. (2017). Perencanaan dan Pengembangan Aplikasi Absensi Mahasiswa Menggunakan Smart Card Guna Pengembangan Kampus Cerdas (Studi Kasus Politeknik Negeri Tanah Laut). Jurnal Integrasi, 84-91 Sitorus, L. (2015). Algoritma dan Pemrograman. Yogyakarta: ANDI. 